\title{
ACTH therapy in infantile spasms: side effects
}

\author{
RAILI RIIKONEN AND MÄRTA DONNER \\ II Paediatric Clinic, Children's Hospital, University of Helsinki, Finland
}

SUMmARY 162 children with infantile spasms were treated with ACTH at the Children's Hospital, Helsinki, and at the Aurora Hospital, Helsinki, during 1960-76. In a large proportion (37\%) of the children the treatment caused pronounced side effects, and the mortality was $4.9 \%$. The most common complications were infections : septic infections, pneumonias, and urinary and gastrointestinal infections. Other side effects were arterial hypertension (11), osteoporosis (2), hypokalaemic alkalosis (2), and other marked electrolyte disturbances (10). In 2 children necropsy showed fresh intracerebral haemorrhages. Four children developed oliguria and hyperkalaemia during and after withdrawal of ACTH. One of them had tubular necrosis confirmed by renal biopsy. Infections were significantly more common with large doses (120 units) of ACTH than with small ones (40 units). It is concluded that side effects, even severe ones, are more common during this treatment than had been assumed. Careful watch is important before and after treatment. The benefit of very high dosages should also be reconsidered.

For 20 years ACTH or corticosteroids has been the treatment of choice in infantile spasms. ${ }^{1}$ Although there are conflicting observations about whether or not it affects intellectual outcome ${ }^{2-8}$ it usually stops the seizures, and there are fewer relapses than after conventional anticonvulsive drugs. Primarily, spasms will be controlled in 60 to $80 \%$ of the children..$^{9-12}$

Daily dosage varies from 20 to 180 units and the duration of treatment from 3 weeks to 6 months. Some give ACTH alone. Others combine it with glucocorticoids, generally with dexamethasone or prednisolone. Despite large doses and long duration, side effects have been considered slight or they have not been carefully investigated..$^{511-13}$ However, severe side effects and fatal results from treatment with ACTH and dexamethasone have been reported from Germany. ${ }^{214-15}$ Sorel $^{16}$ noted that side effects were associated with the use of synthetic ACTH. In our large series ${ }^{17-18}$ treatment with ACTH appeared to cause frequent and sometimes severe side effects.

\section{Materials and method}

In 1960-76 at the Children's Hospital, University of Helsinki, and the Aurora Hospital, Helsinki, 162 children with infantile spasms at the mean age of $9 \cdot 4$ (range 1-32) months were treated with long-acting ACTH. Corticotrophin (Acton prolongatum, Acortan prolongatum, Cortrophin $\mathrm{Z}$ ) was used in 139 patients, its synthetic analogue $\mathrm{Zn}$ tetracosactrin (Synachten Depot, S-Cortrophin Depot) in 23 patients. ACTH was given once a day intramuscularly. In 97 children the daily dosage was 40 units for 3 weeks, 20 units for 2 weeks, and then it was gradually stopped in 1 week. After 1969 larger doses were used. 54 children had daily $120-160$ units for 3 weeks, 60-80 units for 2 weeks, and then it was gradually stopped in 1 week. 11 of the 162 children were treated with ACTH and dexamethasone. ACTH was gradually increased to 80 units a day and this was maintained for 3 weeks or longer if there was no clinical response. After the response the dose was reduced and treatment was continued intermittently with dexamethasone-that is $4-9 \mathrm{mg}$ once a day for 4 days followed by 6 days without. This treatment was continued for 3-4 months and during this time the children stayed on noninfectious paediatric wards. Before starting treatment with ACTH each child was examined to exclude infections by examinations of urine, erythrocyte sedimentation rate and blood cell count, bacterial cultures from nose, throat, and urine, and $x$-rays of the lungs. 10 children received no ACTH, because they had resistant infections ( 3 had cytomegalovirus) and ACTH was considered to carry too great a risk for them. 42 children had been severely retarded since birth or had severe malformations and they were not treated with ACTH since it could not benefit them. Thus, there was some selection for treatment of 214 children admitted with infantile spasms during 1960-76. These 52 children were given conventional anticonvulsants. 


\section{Results}

$60(37 \%)$ children showed pronounced side effects. In $24(14.8 \%)$ the side effects were severe or fatal. Eight $(4.9 \%)$ died during ACTH treatment or after complications of the treatment (Table 1). In none of them was there any minor respiratory infection or minor side effect of hypercortisolism-such as steroid acne, or weight gain and 'moon face'.

With larger dosage of ACTH (usually 120 units), $42.6 \%(23 / 54)$ of children had pronounced side effects. With the smaller dosage (40 units) $35 \%$ $(34 / 97)$ had side effects. During treatment with ACTH and dexamethasone combined $27 \cdot 3 \%(3 / 11)$ had side effects. When synthetic analogues of ACTH were used $69 \cdot 6 \%(16 / 23)$ had side effects. There were more infections with large doses $\left(\mathrm{P}<0.05 ; \chi^{2}=\right.$ $4 \cdot 474)$ and with synthetic analogues of $\mathrm{ACTH}$
(NS; $\left.\chi^{2}=3 \cdot 294\right)$. The number of infections was significantly increased with larger doses.

Infections. Five patients had septic infections during treatment with ACTH, 3 of whom died. Blood cultures showed Staphylococcus aureus (2), Klebsiella pneumoniae (1), Escherichia coli (1), and Proteus vulgaris (1). Some other children were suspected to have sepsis, but no blood cultures were made. 20 had pneumonia, 6 of whom died ( 3 who had a simultaneous sepsis are in this category). In 2 children who died of pneumonia the micro-organism responsible was Pneumocystis carinii.

One child who died had a generalised cytomegalovirus and staphylococcus. His lungs, kidneys, liver, and hypophysis were affected by cytomegalovirus. Another child developed a staphylococcal empyema, which was cured by lung drainage and antibiotics.

Table 1 Lethal outcome of ACTH therapy, 8 cases

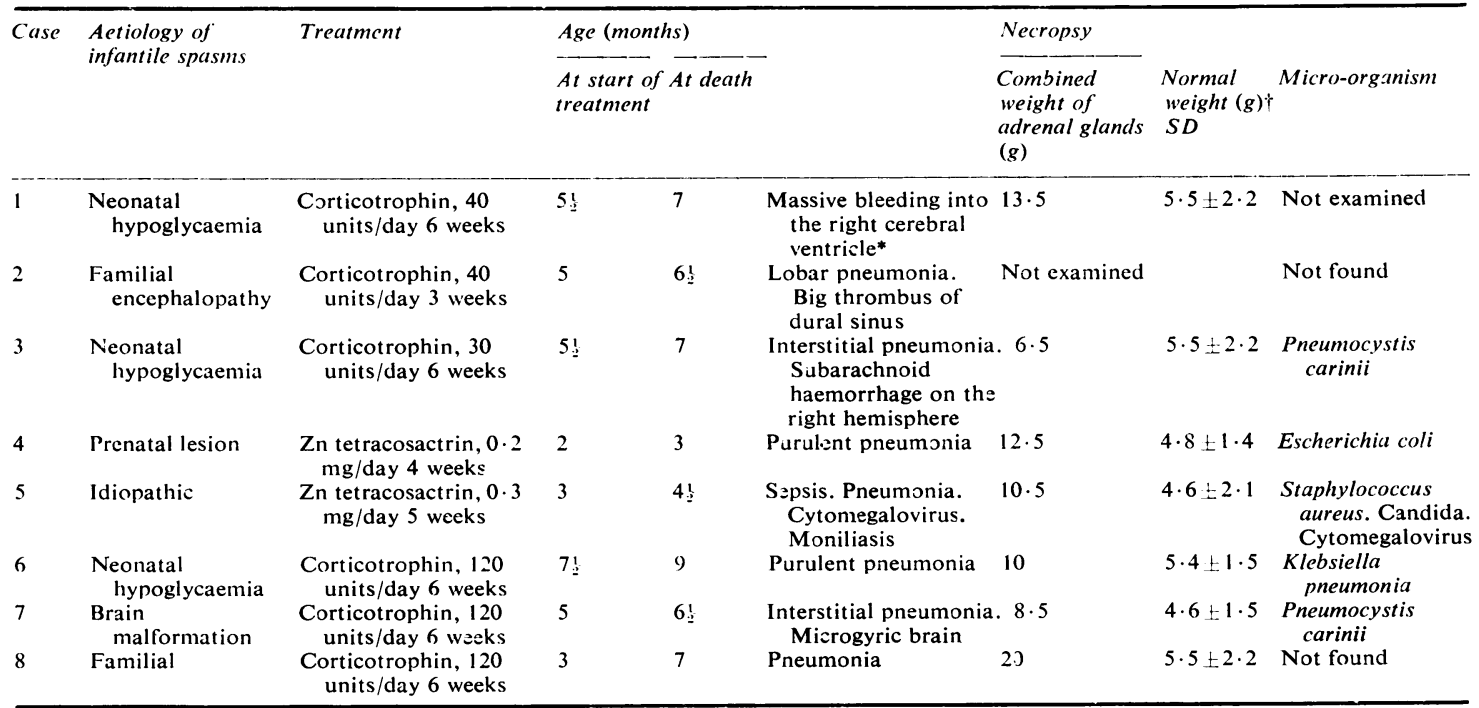

*At start of treatment with ACTH the cerebrospinal fluid was normal.

+ Nornal weight of organs, according to Sshulz et al.42

Table 2 Infections during treatment with ACTH

\begin{tabular}{|c|c|c|c|c|c|}
\hline \multirow[t]{3}{*}{ Treatment } & \multirow[t]{3}{*}{ No of children treated } & \multicolumn{2}{|c|}{ Chi!dren with infections } & \multirow{2}{*}{\multicolumn{2}{|c|}{$\begin{array}{l}\text { Children with septic } \\
\text { infections }\end{array}$}} \\
\hline & & \multirow{2}{*}{ No } & \multirow{2}{*}{$\%$} & & \\
\hline & & & & No & $\%$ \\
\hline Lower doses (20-40 units per day) & $97 \quad(4)^{S}$ & $22 *$ & $22 \cdot 7$ & 5 & $5 \cdot 2$ \\
\hline Larger doses (120-160 units per day) & $54 \quad(5)^{\mathrm{s}}$ & 21 & $38 \cdot 9$ & 1 & $1 \cdot 8$ \\
\hline ACTH and dexamethasone combined & $11 \quad(1)^{s}$ & 2 & $18 \cdot 2$ & $-\rightarrow$ & \\
\hline Synthetic ACTH & 23 & 10 & $43 \cdot 5$ & 2 & $8 \cdot 7$ \\
\hline
\end{tabular}

s Number of children with synthetic ACTH.

$* P<0.05, \chi^{2}=4.474$. 
One child (Case 1) was exposed to tuberculosis during treatment with ACTH. Perhaps her death at age 13 months was due to this infection.

\section{Case 1}

The girl did not have the conventional BCG vaccination during the neonatal period because she had convulsions from age 2 days. Later she developed infantile spasms and was treated with ACTH at age 2 to 3 months. During her stay in hospital she came in contact with a person with cavitating tuberculosis. At age 5 months primary tuberculosis of the lungs was diagnosed and 8 months later she died despite anti-tuberculous therapy. The diagnosis was confirmed at necropsy.

Urinary infections developed during ACTH therapy in 11 patients. One child had a fulminant Proteus mirabilis infection, peritonitis, and uraemia after 2 weeks' therapy with corticotrophin. A purulent infection developed in the right hydronephrotic kidney (detected later by intravenous urography).

One child had a severe and protracted cytomegalovirus infection during treatment with ACTH: meningoencephalitis with fever for many months, and $a$ rise in the erythrocyte sedimentation rate to more than $100 \mathrm{~mm} / \mathrm{h}$. At age 6 years the girl still had pathological CSF findings (high IgG: albumin ratio), which may indicate local production of immunoglobulins in the central nervous system and be interpreted as a sign of a slow virus infection. ${ }^{17}$

Other infections. 10 children had gastroenteritis. Two of them required intravenous rehydration. One child was severely ill and the infection lasted 2 weeks. Candida infections of the oral mucosa were common. In 3 cases the infection was fulminant, in one it extended from the mouth to the larynx, intestines, and lungs.

Four children later had recurrent infections-for example, one of them had 10 attacks of pneumonia and 16 attacks of febrile bronchitis during his lifespan of 7 years. Minor infections were skin abscess (1), furunculosis (1), otitis (2), and fever of unknown origin (4). The role of ACTH in these cases remains obscure.

Hypertension. 11 of the 17 children examined had arterial hypertension, which generally developed in the 2 nd or 3rd week of ACTH treatment. The blood pressure was raised in these 11 children-to $160 / 110$, $180 / 130,280 / 150,200 / 90,210 / 150,140 / 100,160 / 100$, $165 / 100,130 / 100,210 / 160,190 / 100 \mathrm{mmHg}$. One child also had hypertensive ophthalmoscopic findings: strong general arterial narrowing in the fundi. Unfortunately, blood pressure was not measured routinely. After treatment the blood pressure was normal in these children.

Intracerebral haemorrhage. In one case the cause of death was fresh intraventricular cerebral haemorrhage and in another necropsy showed fresh subarachnoid haemorrhage and interstitial pneumonia. The cause of the bleeding remained unknown-for example blood pressure had not been examined.

Osteoporosis. Two children developed osteoporosis during treatment with ACTH. One child had slightly subnormal serum calcium even before therapy $(2 \cdot 00-2 \cdot 4 \mathrm{mmol} / \mathrm{l} ; 8-9.6 \mathrm{mg} / 100 \mathrm{ml})$ but after 2 weeks' therapy both calcium and phosphate levels were low (calcium: $1 \cdot 3-1 \cdot 65 \mathrm{mmol} / 1 ; 5 \cdot 2-6 \cdot 6$ $\mathrm{mg} / 100 \mathrm{ml}$ and phosphate: $1 \cdot 16-1 \cdot 65 \mathrm{mmol} / \mathrm{l}$; $3 \cdot 6-5 \cdot 1 \mathrm{mg} / 100 \mathrm{ml}$ ), normal calcium $2 \cdot 15-2 \cdot 7$ $\mathrm{mmol} / \mathrm{l}(8 \cdot 6-10 \cdot 8 \mathrm{mg} / 100 \mathrm{ml})$ and normal phosphate $1 \cdot 50-2 \cdot 50 \mathrm{mmol} / 1(4 \cdot 8-7 \cdot 8 \mathrm{mg} / 100 \mathrm{ml})$. The other child had normal serum calcium and phosphate values before and during treatment. Alkaline phosphatase was slightly raised before therapy. In both children alkaline phosphatase fell to between half and one-third of the earlier value during treatment with ACTH. Both children also had generalised aminoaciduria. Because of these abnormal findings $x$-rays were taken and these showed pronounced osteoporosis.

Electrolyte disturbances and renal failure. Three children had hypokalaemic metabolic alkalosis (serum potassium $2 \cdot 5-2 \cdot 6 \mathrm{mmol} / \mathrm{l}$ and base excess $+10 \cdot 9-+11 \cdot 0)$ during treatment. 10 children had pronounced disturbances of electrolytes at the end of the ACTH treatment or for a few days after it; these disturbances were often combined with marked changes in weight (up to $\pm 11 \%$ ). Four children had oliguria (Figs 1-4). In one of these four a kidney biopsy was made and this showed tubular necrosis.

Case 2

The early history of the child was uneventful. The birthweight was $3050 \mathrm{~g}$, length $49 \mathrm{~cm}$, and Apgar score 9. Development was normal until age 13 months, when the syndrome of infantile spasms was diagnosed. Despite extensive investigations the reason for the spasms remained unknown. Carotid angiography showed slight left-sided hypoplasia of the brain. The pathophysiological significance of this remained unknown. It may have been the result of a prenatal disturbance or a malformation. At age 14 months ACTH (40 units daily) was started. The primary effect was good; the spasms disappeared 


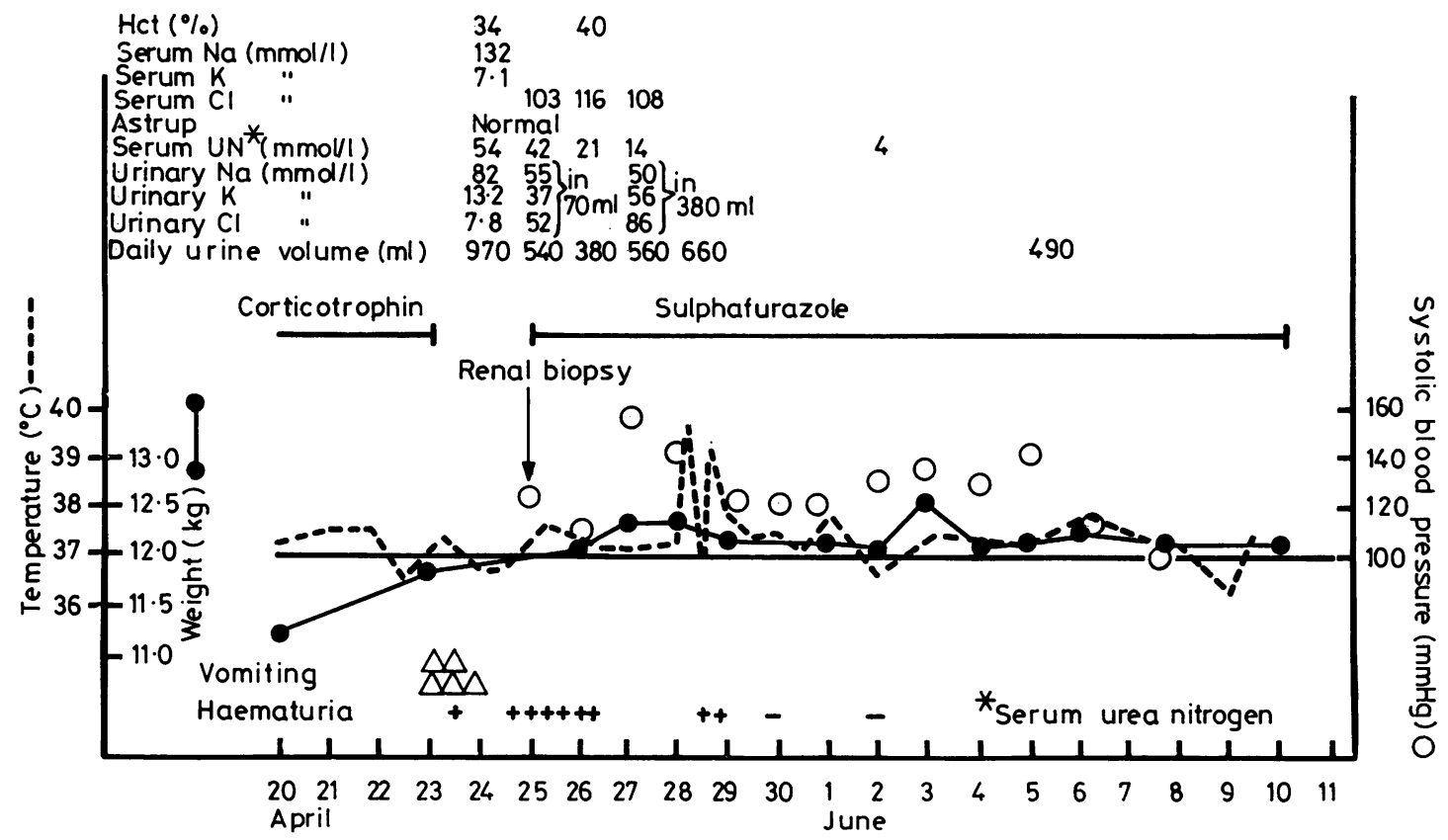

Conversion SI to traditional units-serum urea nitrogen: $1 \mathrm{mmol} / \mathrm{l} \approx 0.71 \mathrm{mg} / 100 \mathrm{ml}$.

Fig. 1 Case 2, child with oliguria after being treated with ACTH for 6 weeks.

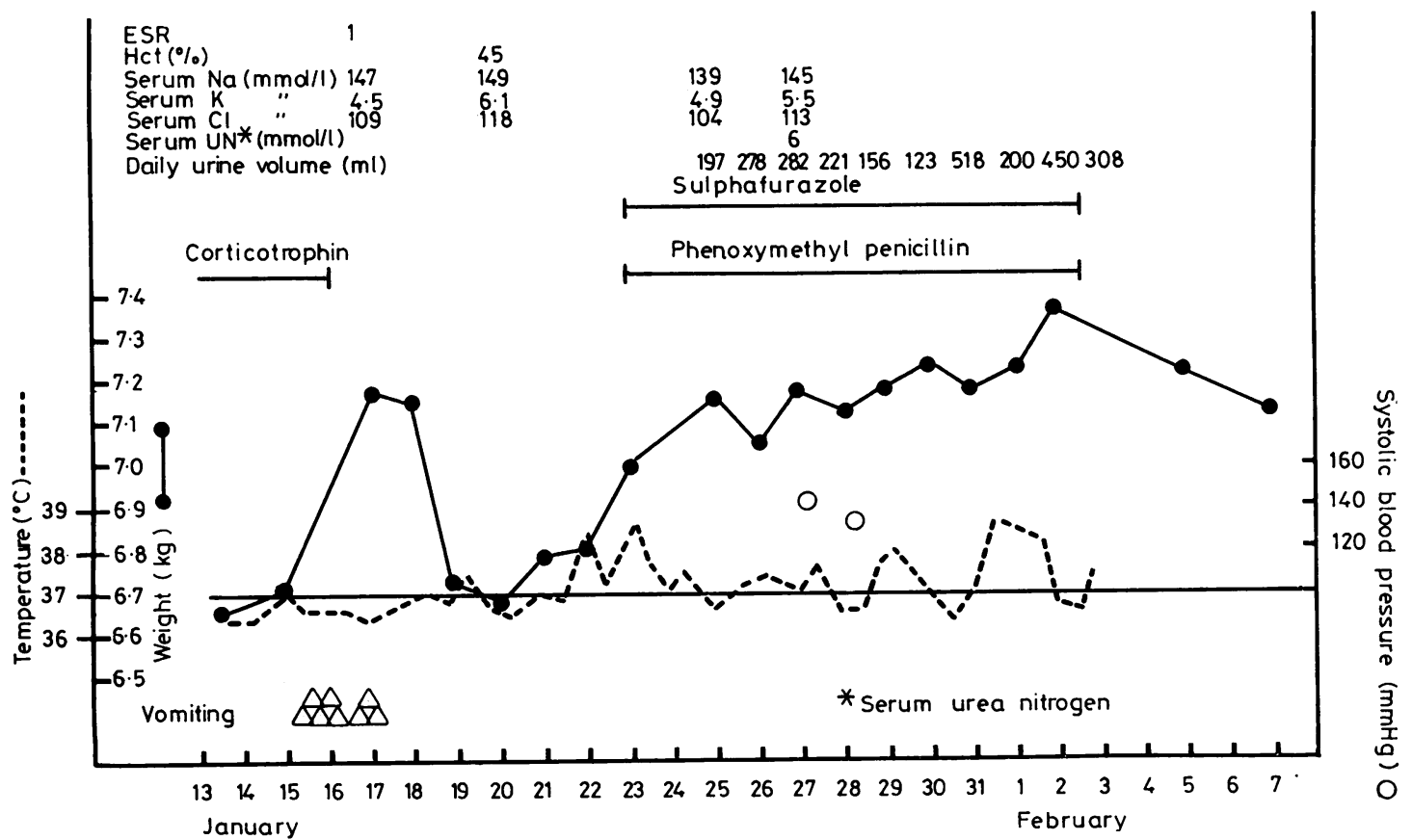

Fig. 2 Case 3, child with oliguria after being treated with ACTH for 6 weeks. 


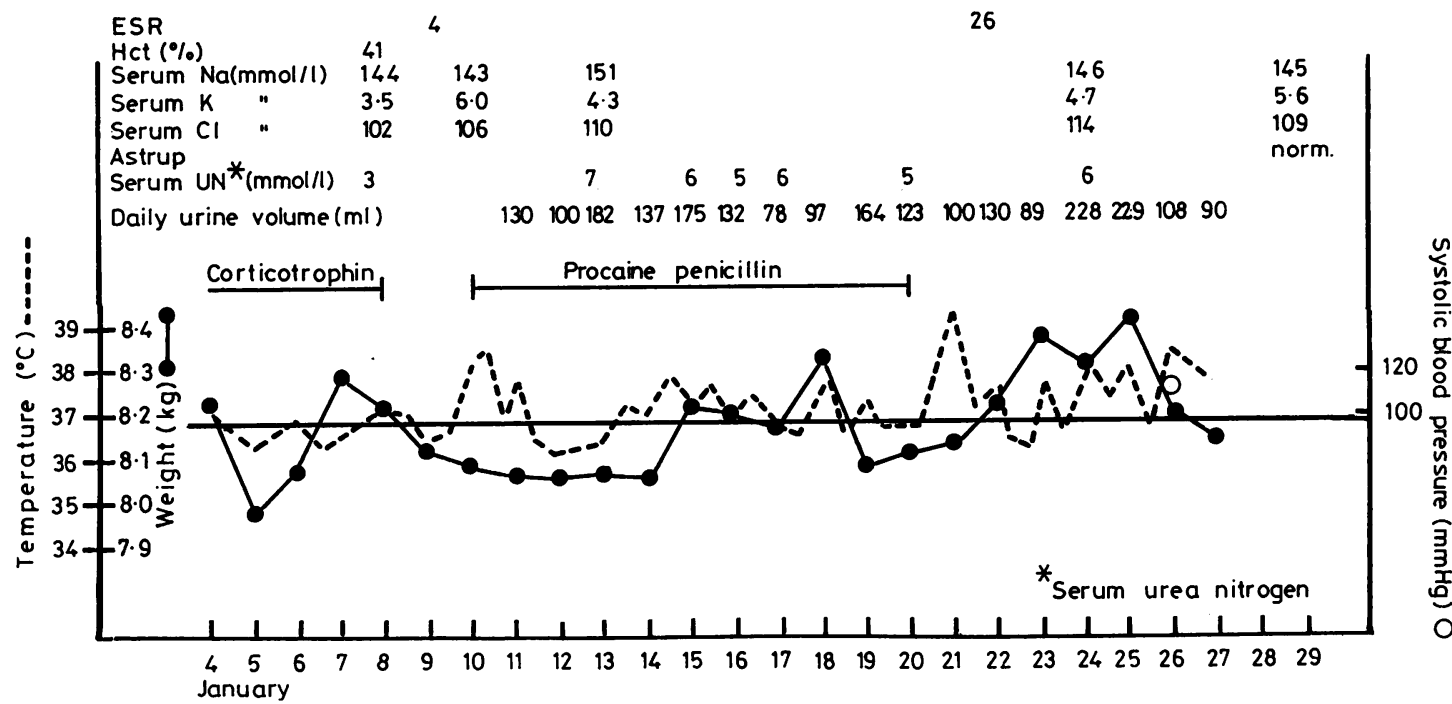

Fig. 3 Case 4, child with oliguria after being treated with ACTH for 6 weeks.

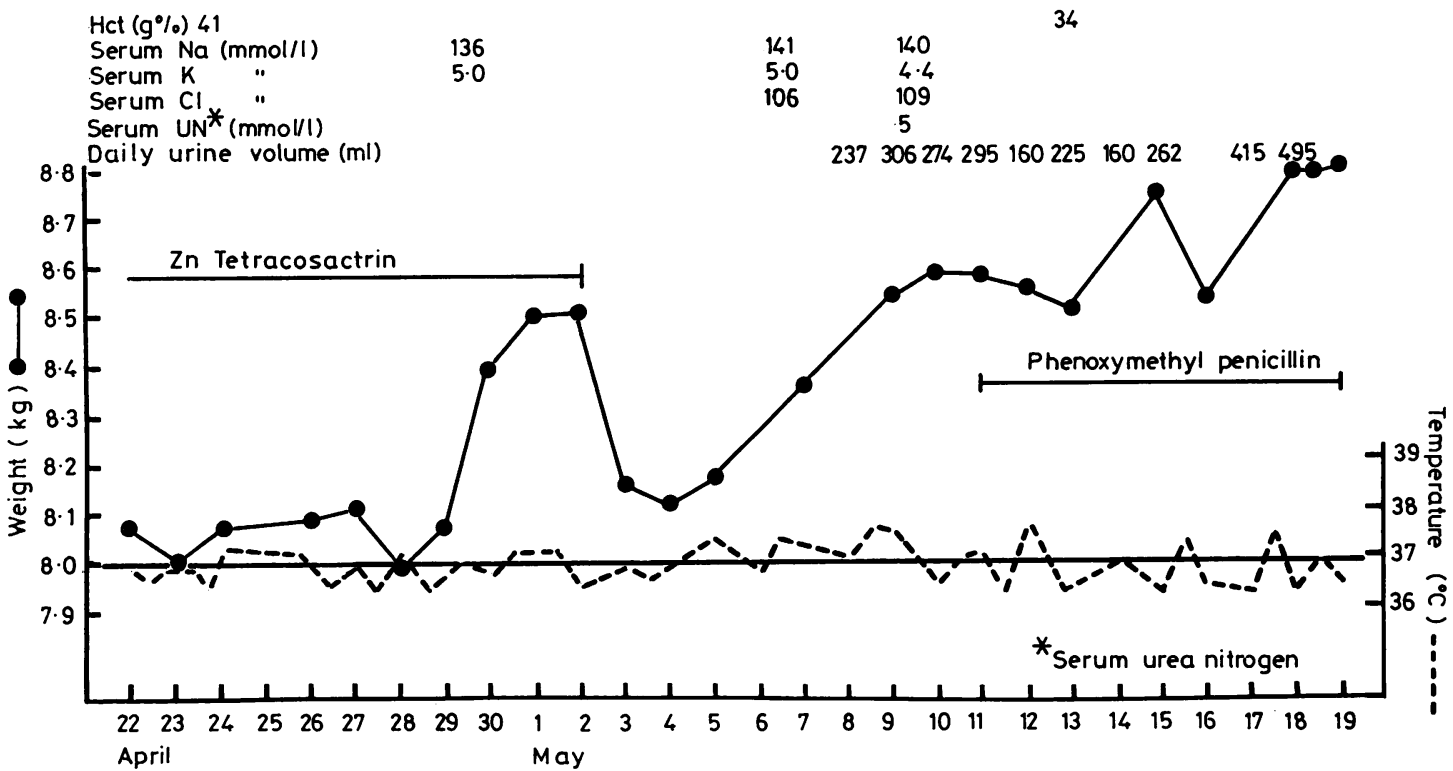

Fig 4. Case 5, child with oliguria after being treated with ACTH for 6 weeks.

during the first week and the encephalogram showed no hypsarrhythmia after 3 weeks. Before ACTH the urine had been normal but 4 days after treatment began pyuria was found in several samples (also obtained by catherisation). Serum creatinine and intravenous urogram were normal and cultures showed no infection.
After $5 \frac{1}{2}$ weeks of treatment the girl started to vomit, oliguria and hyperkalaemia developed, and serum urea nitrogen levels rose to $54 \mathrm{mmol} / \mathrm{l}(75$ $\mathrm{mg} / 100 \mathrm{ml})$, normal levels 4-14 $\mathrm{mmol} / 1$ (6-20 $\mathrm{mg} / 100 \mathrm{ml}$ ). Pyuria was now constantly present and haematuria appeared. Renal biopsy, performed 1 day later, showed slight tubular necrosis. Treatment 
included limitation of water intake, anion exchange resin because of hyperkalaemia, and mannitol to enhance urine flow. The function of the kidneys became normal. Blood urea and creatinine levels and creatinine clearance were normal 10 days later. Intravenous urography, $\mathbf{3}$ years later, was normal.

\section{Case 3}

Neonatal hypoglycaemia was the presumed cause of this child's spasms, which appeared at age 6 months. Before the spasms the boy's development had been normal. Initially ACTH had a good effect, but after 5 weeks he started to vomit and lost $7 \cdot 5 \%$ of his weight. Serum potassium rose to $6 \cdot 1 \mathrm{mmol} / 1$. 10 days after the treatment with ACTH was stopped urine volumes were noticed to be small; however, there was no uraemia. The urine volumes remained small for $\mathbf{8}$ days, but gradually they became normal.

\section{Case 4}

In one child with neonatal hypoglycaemia and neonatal intracranial haemorrhage the diagnosis of infantile spasms was made at age 9 months. The boy had been slightly retarded since birth. ACTH 40 units per day had a good primary effect. Three days after the end of a 6-week course of treatment the urine volumes were noticed to be small and serum potassium was $6.0 \mathrm{mmol} / \mathrm{l}$. Urine volumes remained small for 17 days, but the output returned to normal without any treatment. No uraemia developed.

\section{Case 5}

The early history of this child was normal until age 5 months. She then had a febrile gastroenteritis. Soon afterwards she developed infantile spasms. ACTH ( 50 units a day) had a good effect and was given for 6 weeks. Four days after the end of this period the potassium was at the upper limit $(5.0 \mathrm{mmol} / \mathrm{l})$ and small urine volumes were noticed for a week, the weight gain being $600 \mathrm{~g}$ or $8 \%$ at this time.

Other side effects. Plasma cortisol levels are available as single determinations only in 4 children. During reduction of ACTH dose, 2 days before stopping it, two children had abnormally low values: $0 \cdot 17$ and $0 \cdot 24 \mu \mathrm{mol} / \mathrm{l}(6 \cdot 0-8 \cdot 4 \mu \mathrm{g} / 100 \mathrm{ml})$, normal 0.27-0.69 u.mol/1 (9.7-24.7 ug/ $100 \mathrm{ml})$. The third child had no measurable cortisol. This was examined 8 weeks after treatment with ACTH and dexamethasone combined. The fourth child had a normal cortisol level. Side effects in the 2nd and 3rd weeks of treatment were irritability, sleeplessness, and increased spasticity or apathy. The neurological symptoms seemed to increase. These central effects were severe in 14 cases. One child was suspected to have increased intracranial pressure at the time
ACTH was reduced. He was irritable and had long spells of apnoea. Treatment had to be stopped. Another child developed hydrocephalus with increased intracranial pressure during $2 \frac{1}{2}$ weeks of therapy with $\mathrm{ACTH}$, and a shunt was installed. It remains uncertain whether ACTH played any part in the raised intracranial pressure. Four children had transient glucosuria during ACTH. Amino-acid analysis was done from the urine of 25 , and from the plasma of 4 children. 12 of them had a general renal aminoaciduria during ACTH and 2 also had pronounced changes in plasma amino-acids during ACTH. In one child the thrombocyte count rose to $1000 \times 10^{9} / 1$. The growth of the children was not studied, as many of the underlying diseases were severe and might have affected growth.

\section{Discussion}

ACTH stimulates the secretion of adrenocortical hormones: cortisol, corticosterone, weak androgens and, initially, also aldosterone. Prolonged administration of large doses of ACTH induces hyperplasia and hypertrophy of adrenal cortex (Table 1). Most therapeutic effects of ACTH are probably mediated by glucocorticoids. But ACTH also has direct, less well understood, effects on various organs, including the central nervous system. ${ }^{19-24}$

Glucocorticoids suppress each stage of the immune response. Not only are bacterial infections enhanced by ACTH treatment, but also viral ones. Latent cytomegalovirus infections may flare up ${ }^{17}$ or take an unusual course. $P$. carinii may be a cause of severe lung infections, as in our 2 patients. Other infections - such as measles and varicella which are known to cause severe disease during immunosuppressionmay also become dangerous during treatment with $\mathrm{ACTH}$. In this series we especially tried to exclude infections before starting treatment and to avoid them during it. During ACTH therapy it is more difficult to diagnose an infection, because analysis of the blood is affected by cortisol giving rise to leucocytosis and neutrophilia. Despite our efforts even severe infections were not avoided.

The host response and immunological function are altered in relation to glucocorticoid dosage. In our series the risk of infections seems to have been greater when larger doses of ACTH were used. Synthetic analogues seem to carry a greater risk of infections than natural ACTH. ${ }^{16}$ This appeared to be so in our series too.

The incidence of osteoporosis is lower with ACTH than with glucocorticoids. In our series only 2 cases were found, but no systematic search was made. Cret et al. ${ }^{25}$ described 5 children with infantile 
spasms who developed osteoporosis, hypocalcaemia, hypophosphataemia, and low alkaline phosphatase in blood during $\mathrm{Zn}$ tetracosactrin.

One child also had hypomagnesaemia. Glucocorticoids inhibit intestinal calcium absorption. The resultant hyperparathyroidism may be of major importance in the pathogenesis of osteopenia. ${ }^{26-27}$ Furthermore, serum 1-25-dihydroxyvitamin- $D_{3}$ is reduced in children receiving glucocorticoids. ${ }^{28}$

Excessive doses of ACTH (100-180 units) increase the 24-hour urinary-free cortisol to about 20- or 30fold. ${ }^{29-30}$ The mineralocorticoid effects of cortisol, corticosterone, and desoxycorticosterone presumably play a significant role in the production of undesirable effects of ACTH treatment-such as hypertension, and sodium and fluid retention.

Of the 11 children who were observed to have hypertension 8 had received $\mathrm{Zn}$ tetracosactrin, generally in doses of 80 units. This synthetic hormone seems to carry a considerable risk of hypertension, but whether this risk is smaller with corticotrophin remains unknown.

In our hospitals blood pressure is not routinely measured in infants and perhaps a higher proportion of the children had arterial hypertension than is reported. The intracerebral haemorrhage found in 2 cases at necropsy may have been due to hypertension. Taeusch et al. ${ }^{31}$ reported intraventricular haemorrhage in 6 out of 7 infants with respiratory distress treated with glucocorticoids. The mechanism by which steroid treatment could lead to intracerebral haemorrhage remains unknown. Blood pressure was measured neither in these cases nor in our fatal cases.

Plasma cortisol levels reach a maximum after 10 days of ACTH administration. ${ }^{14}$ In our series hypokalaemia, alkalosis, and hypertension were found during the 2nd and 3rd weeks of such treatment. This often coincided with an increase in the neurological symptoms. It has been suggested that this is due to cerebral oedema resulting from retention of salt and water, or to hypertensive encephalopathy. ${ }^{32-33}$ Now it is known that cortisol and ACTH have direct effects on the brain ${ }^{19}{ }^{34-37}$ and that chronic administration of cortisol increases brain exitability although the concentration of sodium and potassium in the spinal fluid and the brain remains normal. .8-39 $^{38-3}$

During ACTH treatment the greatly increased mineralocorticoid activity will presumably suppress the renin-angiotensin-aldosterone axis. After withdrawal of ACTH the secretion of cortisol, corticosterone, and desoxycorticosterone will decrease precipitously while the renin-angiotensin-aldosterone axis needs time to recover. A sudden mineralocorticoid and glucocorticoid deficiency will thus ensue. The mineralocorticoid deficiency will tend to lead to a hypo-osmolal contraction of the extra- cellular volume, and may result in renal failure. The glucocorticoid deficiency adds to the picture of an impaired water excretion capacity. This complexity of disturbance in fluid regulation may explain why losses and gains in weight were observed (Figs 1-4). These withdrawal symptoms had not been reported previously. It is important to know whether the child enters a negative or positive water balance and whether he needs water restriction and diuretics, or more fluids. Glucocorticoid substitution may be necessary after ACTH treatment. We are now trying to analyse the mechanisms of disturbance.

In this series, large doses of ACTH (usually 120 units) gave more side effects than smaller doses (40 units), but the difference was not statistically significant. Infections were however, significantly increased with large doses $\left(P<0.05, \chi^{2}=4.474\right)$. During treatment with ACTH and dexamethasone combined there were fewer side effects than with other treatment schedules $\left(P<0.05, \chi^{2}=4.556\right)$. The children in this group were not treated as inpatients during the whole time and side effects were not so carefully recorded. It is therefore difficult to compare them with the others.

When synthetic analogues of ACTH were used $16(69 \cdot 6 \%)$ out of 23 children had side effects. Eight had hypertension, 3 electrolyte imbalances, and 10 infections. Three of these side effects were severe: long-lasting, severe gastroenteritis in one, and two fatal cases of sepsis. There were considerably more side effects in this group. ACTH produces less impairment of HPA function and growth in children than glucocorticoids. This advantage may be lost if a preparation with too-prolonged an action is usedsuch as $\mathrm{Zn}$ tetracosactrin. ${ }^{29}$

We believe that ACTH (or perhaps in future its fragments with fewer side effects), ${ }^{14}$ alone or combined with glucocorticoids, will maintain its position as the primary drug for the treatment of children with infantile spasms. However, as such treatment has pronounced side effects, a careful watch is essential especially by measuring the blood pressure, examining electrolyte levels, and trying to detect and treat infections early. The appearance of osteoporosis, hypertension, hypokalaemic alkalosis, or exaggerated neurological symptoms should lead to reduction of the dose. If hypertension and salt retention cannot be controlled by salt restriction, dose reduction, or antihypertensive drugs, it is better to change to synthetic glucocorticoids (methylprednisone) which have a less sodium-retaining effect. Often diuretics are given to children with fluid retention during treatment with ACTH. As they increase the potassium loss they are recommended only with regular potassium determinations and perhaps with supplementary potassium. 
As side effects, especially infections, seemed to be dose-dependent, the dose should be the lowest that will control the symptoms. The benefit of very high dosages should be reconsidered. Our mode of treatment is based on the clinical experience of Hagberg ${ }^{5}{ }^{40}$ and Gamstorp ${ }^{41}$ in Sweden who both consider large doses of ACTH important. In other countries considerably smaller ACTH doses are used. Thorough investigations concerning the optimal dosage of ACTH have not been reported. The use of $\mathrm{Zn}$ tetracosactrin is not recommended; it has more side effects and can have a fatal outcome. The use of anticonvulsant drugs-such as nitrazepam-as primary treatment should be considered, particularly for instance, if the benefit from ACTH is questionable, as in the case of an already severely damaged child. Furthermore, if the child is known to have a cytomegalovirus infection treatment with ACTH should be avoided. ${ }^{17}$ In future, it will probably be possible to test every child for latent cytomegalovirus infection by a rapid method-for example, by fluorescent antibody test. We think it is important to look for other patients in whom treatment with ACTH would be unsuitable.

More knowledge should be gained of the clinical and biochemical actions of ACTH and glucocorticoids in the treatment of infantile spasms. The drugs are used in excessive dosage and for a long time during a period of very active development of the brain-for example, myelinisation has its maximum at the time that infantile spasms usually begin.

We thank Professor J Perheentupa for help.

This study was supported by the Foundation for the Research Institute, Rinnekoti Institution for Mentally Retarded, Espoo, Finland.

\section{References}

1 Sorel L, Dusaucy-Bauloye A. A propos de 21 cas d'hypsarhythmia Gibbs: son traitement spectaculaire par l'ACTH. Acta Neurol Belg 1958; 58: 130-41.

2 Matthes A, Mallmann-Mühlberger E. Die PropulsivPetit-Mal-Epilepsie und ihre Behandlung mit Hormonen. Dtsch Med Wochenschr 1963; 88: 426-34.

3 Petersen C E, Doose H, Himmelmann H R. Die psychomotorische Entwicklung von Kindern mit Blitz-NickSalaam-Krämpfen mit und ohne Hormone-behandlung. Med Welt 1964; 2: 1947-51.

4 Snyder C. Infantile spasms. Favorable response to steroid therapy. JAMA 1967; 201 : 198-200.

5 Hagberg B, Nilsson D, Rasmussen P. ACTH och infantil spasm-analys av 48 fall med gott behandlingsresultat (English abstract). Läkartidningen 1977; 74: 1602-4.

6 Jeavons P M, Bower B D. Treatment and prognosis. In: Infantile spasms. A review of the literature and a study of 112 cases. Clinics in Developmental Medicine No 15. London: Spastics Society/Heinemann Medical, 1964: 50-63.
7 Jeavons P M, Harper J R, Bower B D. Long-term prognosis in infantile spasms: a follow-up report on 112 cases. Dev Med Child Neurol 1970; 12: 413-21.

8 Jeavons P M, Bower B D, Dimitrakoudi M. Long-term prognosis of 150 cases of 'West syndrome'. Epilepsia 1973; 14: $153-64$.

9 Hellström B, Oberger E. ACTH and corticosteroid treatment of infantile spasms with hypsarhythmia. Acta Paediatr Scand 1965; 54: 180-7.

10 Alvin A, Billing B, Hagberg B, et al. Kortikotropin vid infantil spasm med hypsarytmi (English abstract). Nord Med 1966; 75: 234-7.

11 Oftedahl S-I. Behandling av infantile spasmer med hypsarytmi (in Norwegian). Tijdschr Norske Laegefor 1970; 90: 1621-5.

12 Jeavons $\mathbf{P}$ M, Bower B D. Infantile spasms. In: Vinken P J G, Bryn G W, eds. Handbook of clinical neurology. New York: Elsevier, 1974.

13 Lacy J R, Penry J K. Infantile spasms. New York: Raven Press, 1976.

14 Willig R P, Lagenstein I, Iffland E. Cortisoltages profile unter ACTH-und Dexamethason-Therapie frühkindlicher Anfälle (BNS-und Lennox-Syndrom). Monatsschr Kinderheilkd 1977; 126: 191-7.

15 Lagenstein I, Willig R P, Iffland E. Behandlung frühkindlicher Anfälle mit ACTH und Dexamethason unter standardisierten Bedingungen. I. Klinische Ergebnisse. Monatsschr Kinderheilkd 1978; 126: 492-9.

16 Sorel L. 196 cases of infantile myoclonic encephalopathy with hypsarrhythmia (IMEH: West syndrome) treated with ACTH: danger of synthetic ACTH (abstract). Electroencephalogr Clin Neurophysiol 1972; 32 : 576.

17 Riikonen R. Cytomegalovirus and infantile spasms. Dev Med Child Neurol 1978; 20: 570-9.

18 Riikonen $R$, Donner $M$. Incidence and aetiology of infantile spasms during the period 1960-76. A population study in Finland. Dev Med Child Neurol 1979; 21 : 333-43.

19 Korányi L, Beyer C, Guzmán-Flores C. Effect of ACTH and hydrocortisone on multiple unit activity in the forebrain and thalamus in response to reticular stimulation. Physiol Behav 1971; 7 : 331-5.

20 Miller L H, Kastin A J, Sandman C A, Fink M, Van Veen W J. Polypeptide influences on attention, memory, and anxiety in man. Pharmacol Behav 1974; 2 : 663-8.

21 Palo J, Savolainen H. The effect of high doses of synthetic ACTH on rat brain. Brain Res 1974 ; 70: 313-20.

22 Reith M E A, Schotman P, Gispen W H. Hypophysectomy, ACTH1-10 and in vitro protein synthesis in rat brain stem slices. Brain Res $1974 ; 81$ : 571-5.

23 Urban I, Lopes da Silva F H, Storm van Leeuwen W, de Wied D. A frequency shift in the hippocampal theta activity: an electrical correlate of central action of ACTH analogues in the dog? Brain Res 1974; 69: 361-5.

24 de Wied D. Peptides and behaviour. Life Sci 1977; 20: 195-204.

25 Cret L, David M, Macebéo V, Frédérich A, Jeune M. Maladie des spasmes en flexion: troubles cliniques et métaboliques observés en cours de traitement par le tétracosactide zinc. Pediatrie $1976 ; 31$ : 33-48.

26 Hargis G K, Bowser E N, Henderson W J, Williams G S. Radioimmunoassay of rat parathyroid hormone in serum and tissue extracts. Endocrinology 1974; 94: 1644-9.

27 Adams J S, Lukert B P. Correction of corticosteroid induced aberrations of calcium, PTH, and vitamin $D$ by calcium infusion (abstract). Clin Res 1975; 23: 534.

28 Chesney R W, Hamstra A J, Mazess R B, DeLuca H F, O'Reagan S. Reduction of serum-1,25-dihydroxyvitamin$\mathrm{D}_{3}$ in children receiving glucocorticoid. Lancet 1978; ii : 1123-5. 
29 Myles A B, Daly J R. Corticosteroid and ACTH treatment. Principles and problems. London: Arnold, 1974.

30 Eneroth Ol, Gustafsson J-Ä, Ferngren H, Hellström B. Excretion and anticonvulsant activity of steroid hormones in an infant with infantile spasm and hypsarrhythmia treated with excessive doses of ACTH. J Steroid Biochem $1972 ; 3: 877-87$.

31 Taeusch H W, Wang N S, Baden M, Bauer C R, Stern L. A controlled trial of hydrocortisone therapy in infants with respiratory distress syndrome. II. Pathology. Pediatrics 1973 ; 52: 850-4.

32 Hoefer P F A, Glaser G H. Effects of pituitary adrenocorticotropic hormone (ACTH) therapy: electroencephalographic and neurophysiatric changes in fifteen patients. JAMA 1950;143: 620-4.

33 Lowell F C, Franklin W, Beale H D, Schiller I W. Occurrence of convulsive seizures during treatment of asthma with cortisone acetate. $N$ Engl J Med 1951; 244: 49-52.

34 de Wied D, Weijnen J A W M, eds. Pituitary, adrenal, and the brain. Proceedings of an International Conference on the Pituitary-Adrenal Axis and the Nervous System, Vicrhouten, Netherlands, 22-24 July 1969. Progress in Brain Research. Vol. 32. Amsterdam: Elsevier, 1970. 1-357.

${ }^{35}$ Feldman S, Dafny N. Effects of cortisol on unit activity in the hypothalamus of the rat. Exp Neurol 1970; 27:375-87.

${ }^{36}$ Feldman S. Electrical activity of the brain following cerebral micro-infusion of cortisol. Epilepsia 1971; 12: 249-62.

37 Ballard P L, Baxter J D, Higgins S J, Rousseau G C, Tomkins G M. General presence of glucocorticoid receptors in mammalian tissues. Endocrinology 1974; 94 : 998-1002.

38 Oppelt W W, Rall D P. Production of convulsions in the dog with intrathecal corticosteroids. Neurology (Minneap) $1961 ; 11$ : 925-7.

39 Dukes M N G. Side effects of drugs annual 1. A worldwide yearly survey of new data and trends. Amsterdam: Excerpta Medica, 1977.

40 Hagberg B. The nosology of epilepsy in infancy and childhood. In: Birkmayer W, ed. Epileptic seizures, behaviour, pain. Berne: Huber, 1976.

41 Gamstorp I. Pediatric neurology. New York: Meredith Corpn, 1970.

42 Schulz D M, Giordano D A, Schulz D H. Weights of organs of fetuses and infants. Arch Pathol Lab Med 1962; 74: $244-50$.

Correspondence to $\mathrm{Dr} \mathbf{R}$ Riikonen, Paediatric Department, Regional Hospital of Porvoo, SF-06200 Porvoo 20, Finland.

Received 12 July 1979 